\title{
Alternatives, Writing, and the Formulation of a Thesis*
}

\author{
JONATHAN ADLER Brooklyn College, CUNY
}

\section{The Dilemma of Scope and Content}

The teaching of critical thinking, like reading or writing, is dogged by a dilemma of transferability. If writing or thinking "skills" are taught through a specific subject, e.g. teaching writing through literature, then the skill learned is parochial to that subject. The instruction fails to teach these skills so that they are applicable to any subject. The other horn of the dilemma is that if these skills are taught in a content-free (process dominated) way, so as to be widely transferable, then they can develop only the most superficial of skills. This horn of the dilemma is correct in assuming that maximum transferability is purchased at the cost of superficiality. ${ }^{1}$

However, the dilemma is false if compromise is possible: a modest increase in content which sacrifices scope of application, but gains in depth and relevance. I shall attempt to develop one specific proposal which indicates a promising middle road between the two horns of this dilemma.

\section{Alternatives and Discriminating Reasons.}

The widely cited, widely transferable advice that one should offer reasons or good reasons for a position is an instance of impalement on the scope horn. For the advice doesn't address the hard and pertinent questions, concerning what counts as support rather than irrelevance, and what consitutes a good reason. Sometimes the advice goes from the weak to the arbitrary: give two reasons for your thesis. Further, as banal as these bits of advice are, they may still manage to be pernicious. For, as Karl Popper has repeatedly emphasized, ${ }^{2}$ it is all too easy to find support for a position. Such support helps one avoid the unwelcome task of criticizing one's own view. However, if we develop a notion of alternatives to a thesis, more substantive, but still quite general, guidance can be offered such as: Try to find reasons in favor of your position that shows it to advantage over its best competing alternative i.e. that distinguishes it from the best competitor.

An alternative to a thesis will refer to any other statement that cannot be simultaneously true with it. Among these, it is worthwhile to distinguish the contradiction from the contraries. To the claim that, say, "The getaway car was yellow," the contradiction would be "The getaway car was not yellow." The contraries would include, let's assume: "The getaway car was blue," "The getaway car was green," and "The getaway car was orange."

Because the contradiction of a thesis is just the denial of the original claim, it is the easiest alternative to find and support. The contraries imply not just a denial of the original claim but a positive claim that itself must be established. However, the contradiction is also the most difficult to refute, since it is the weakest claim incompatible with the thesis.

But the above alternatives are misleadingly easy illustrations. These alternative views are contraries simply 
because each contains a different semantically contrary term-yellow, blue, green, and orange. Typically, however, the alternatives to a thesis will not be contrary by virtue of semantic contrast, but by virtue of background assumptions or knowledge.

For example, consider the following two theses:

(1) The fetus is a person.

(2) Only beings capable of desires for certain goods can have a right to those goods.

(1) and (2) by themselves do not conflict. But within the present debate concerning abortion, they are premises for sharply opposed positions. The former supports anti-abortion positions; while the latter is central to a subtle and complex pro-choice argument. (1) and (2) only become competitors relative to certain background assumptions. When I use "alternatives," I will always mean "competing alternatives."3

For an initial application consider the thesis that:

U.S. Corporations should divest their holdings in South Africa.

A student supporting this thesis will, of course, appeal to the evils of apartheid. But this reason does not discriminate between the above thesis and various reasonable alternatives which also oppose apartheid. Proponents of these alternatives argue that the labor forces operating American businesses in South Africa are not racially segregated and their presence allows for strong internal economic pressure upon the South African government.

However wrong and perhaps selfserving such a view may be, it can only be answered by going much further than citing the injustice of apartheid. A genuinely discriminating reason is, for example, that the present climate of active revolt makes South Africa a different situation than the quite common and, arguably, economically necessary cir- cumstance of American businesses investing in countries with undemocratic, oppressive governments. Divestment is now supported as not only morally demanded, but, if that is not enough, as likely to be politically effective. A discriminating reason offers then a reason that supports a thesis by showing it to advantage over a specific alternative.

The flip side of the empty, but potentially pernicious, advice to offer reasons is that students should criticize opposing views. The emptiness is in the failure to provide a basis for evaluating the importance and relevance of different possible criticisms. The perniciousness is in the easy slide to a view of criticism as simply a search for objections, whose aim is refutation or rejection.

The search for significant discriminating reasons, however, places a premium on recognizing areas of agreement. In the above example, the discriminating reason offered was based on the substantial point of agreement that apartheid should be ended. As this was common ground, the ensuing criticism was more pointed, alleging a failure of the anti-divestment position according to its own commitments. Searching for substantial agreement as a basis for criticism marks an interest in dialogue, rather than quick, decisive dismissal. ${ }^{4}$

\section{Writing and the Formulation of a Thesis.}

Although the concept of alternatives is helpful throughout the writing of the argumentative essay, I will concentrate on its application to the formulation on the thesis. That topic is of crucial importance, as it sets the standard to which the argument aspires, yet it is widely neglected. ${ }^{5}$ For any thesis students choose, that thesis should be neither certain nor highly unlikely. So I want to suggest imposing the following reasonable alternative standard:

A thesis must have at least one 
reasonable, but not certain, alternative.

We want theses and alternatives that, at least, meet all simple and obvious objections. Students' arguments are to be directed to defending their thesis in contrast to the specified alternative as illustrated below.

Clearly, a further step can be made:

A thesis that is reasonable, but not certain, will gain in significance to the extent that an alternative can be shown to be increasingly plausible.

The author says to the reader: The following ... is a plausible thesis for such-and-such reasons. Nonetheless I will show you instead. 6

\section{A Classroom Application.}

After listing various issues involving free speech 1 asked students to formulate theses. Discussion followed over a few classes. Students were then asked to revise their theses. Not unrepresentative as an initial proposal was this one:

(3) We shouldn't have censorship.

This thesis had to be quickly revised in the face of the consensus on the alternative that

(4) Some censorship is permissible when it comes to material that is available to children or minors.

The thesis (3) also seemed too broad since, as many of us in the class noted, there are many different types of censorship.

In order to modify a thesis given an accepted alternative [e.g. (4)], the writer should initially attempt to find the minimal change in the original thesis that retains its simplicity and generality. It should not be a restatement of the original thesis with an exception clause added on.

To help with the proper formulation of the thesis, we (myself and other members of the class), elicited from the writer a rough idea of the views with which he disagreed. After discussion, the student formulated the following alternative as an expression of those opposing views:

(5) Censorship is permissible in public schools, even for works of proven merit.

But now, given the above concessionthat censorship is justified for minorsthe writer had to have more respect for the alternative (5) than he had initially. He couldn't simply dismiss it as a glaring violation of free speech. He still opposed (5), so following the guidelines for modification of a thesis (see paragraph above), he tried this:

(6) All works of interest and of proven literary or intellectual merit should be available in public schools, at least in the upper grades.

But it was quickly noticed that this is implausible: the school budget is not unlimited. So finally the student's thesis became:

(7) All works of interest and of proven literary or intellectual merit should be available in public schools at least in the upper grades. If selection among them must be made, it should also be determined solely by merit and interest.

The thesis is now reasonably worth defending-it meets the reasonable alternative standard. Making the thesis more contentious is a secondary effect of the basic goal, which is to represent opposing views in a fair way. While further improvement of the thesis is possible, we should now have enough for illustrative purposes.

\section{Alternatives: Justification and Discovery}

Justification for giving centrality to the concept of alternatives and, specifically, for imposing the reasonable alternative standard is two-fold: epistemological and pedagogical. Epistemologically, we briefly mention four points. First, economy is gained by sticking to the crucial points of disagree- 
ment. Second, we can be as fallible in what we reject as we can be gullible in what we accept. (". . . Democracy is the worst form of government," Winston Churchill remarked, "except all the other forms that have been tried from time to time." Echoing this reasoning, Maurice Chevalier quipped "Old age is not so bad when you consider the alternatives. ")

Third, and related to fallibility, the growth of knowledge must be conservative. ${ }^{7}$ We must preserve as much prior belief as possible: to reject too much of what is already accepted is to undermine our basis for understanding and evaluating new claims. (We should also note here the desirability of maintaining a respect for past traditions of inquiry). Selection of a class of relevant alternatives, from the totality of possible alternatives, promotes this kind of conservatism. It severely narrows down the range of beliefs that will be subject to challenge at any one time.

Fourth, real theses or hypotheses are usually complex. Unless we locate them with respect to the alternatives that they actually are intended to oppose, we do not have a grasp on which aspects of these theses or hypotheses are intended as presuppositions or assumptions, and which are meant as the main points requiring defense. So without locating theses or hypotheses with regard to alternatives we do not, for purposes of analysis, properly understand them.

Pedagogically, the animating motivation is simply that an essay should be worthwhile to write and to read. If there is no reasonable alternative, then the thesis is likely to be trivial. If the only viable alternative is certain, then the thesis is too far-out. In one case, the paper is not worthwhile because it is a waste of effort to support what no one controverts, and in the latter case, it is not worthwhile, because it is very doubtful that what is written will go far in establishing the thesis.

One of the most valuable lessons from a systematic presentation and use of the logic of alternatives is that there usually is a far greater variety of theses available than is captured in simple procon oppositions. This lesson undermines our natural bent-well evidenced in public debates-to represent opposing positions in their most extreme, and consequently, normally weakest, form. On the issue of hereditary vs. environmental explanations of intelligence or social behavior, for example, we frequently see the only available views described as complete determination by heredity or complete determination by environment.

But neither of these extreme theses is maintained by any credible participant in the debate. The debate concerns the relative influence of each factor-the differences are ones of degree (and no less significant for that!). Here, the emphasis on alternatives makes its greatest contribution: pushing us, against our inclination, to represent fairly the strengths in opposing views. The thesis that heredity plays a large, but not exclusive, role in the determination of IQ, to continue the example, is much more difficult to refute than the extreme (straw-man) hereditary position. So if we are opposed to genetic determinism, we accept a greater challenge in stating that thesis in a more modest, plausible way.

In promoting a search for alternatives between the obvious extremes, options are expanded. Conclusions are less likely to be gross overstatements of what an essay can accomplish. Frequently, students expect that since an argument results in a conclusion, the thesis must sound conclusive: "Capital punishment is wrong."

Most of us know antecedently, though, that in a brief essay only a small contribution can be made to a topic of this scope. It would be better to receive formulations of conclusions that are fitting to what the essay can possibly do and that begin to mine the wide variation in theses possible on any issue: "I have argued against capital punishment, but I have yet to answer the following 
objections..." or "Capital punishment, then, is wrong generally, though not for cases of espionage ${ }^{\prime \prime}$ or theses that reject the terms of the debate: "Capital punishment is not a significant factor in lowering the crime rate; what matters is how we alter the circumstances that encourages violent crime." Notice that these latter theses are more manageable as assignments. These less dramatic claims focus inquiry and foster an important kind of honesty in limiting goals to what can reasonably be accomplished in the time and space allotted.

\section{Five Objections}

Objection: Between the dull and the unreasonable lies so vast a range that the standard for an adequate formulation is too easy to meet.

Reply: There is truth in this objection even when we take account of the suggestion above (sec.3) for extending the reasonable alternative standard. In any case, if my illustrations and anecdotal evidence is at all typical, the initial range of theses students choose is simplistic, vague, and do not join the issues. Given that starting point, we may still accomplish much even with standards that are not terribly demanding.

Objection: Students may very well write a good essay on a thesis that is either obvious or off-the-wall.

Reply: This is a bit like a student defending his decision to drop out of school by noting that Einstein did not graduate from high school either. The reply is that we have to go on the best evidence available. Although not certain, it is likely, that you will not be very successful if you drop out. Similarly, it is likely that you will write a dull or foolish essay if your thesis is either trite or far-fetched.

Objection: Sometimes the only relevant alternative is the contradiction of the thesis; sometimes the relevant alternatives can be known only with research; and sometimes finding the relevant alternatives is a giant creative step.

Reply: Agreed. There are precise claims where there are no good contrary theses. Someone wishing to defend the thesis that "The dinosaurs were destroyed due to a cataclysmic impact of comets upon the earth," can meet my criterion without developing a viable contrary. For this hypothesis is plausible and not certain, while there may be no viable alternative hypothesis in the running. ${ }^{8}$

Next, we come to the objection that alternative hypotheses or theses, such as hypotheses to explain the destruction of the dinosaurs, are often great creative acts that shouldn't be expected of students, certainly not of freshman writing students.

Again, fair enough. But just as we do not demand in a successful science course that students come up with new hypotheses, so we shouldn't in freshman composition or critical thinking courses. The main learning experience is not in conjecturing a bold new thesis, but in admitting that there is a good alternative and appreciating its force.

Objection: Approaches that use controversial issues to engage students' interests and to highlight the importance of examining different positions has been tried (and tried) without distinctive success. Thus, Wayne C. Booth commenting on the movement to have students write about political controversies and "social problems in which they are personally involved," says that it "now seems almost dead."

Reply: Since this is the position that my view is most readily assimilated to, it is the one to most distance myself from.

Obviously, the notion of alternatives applies to many theses, not just those characterizing controversial issues. One main point of giving that notion centrality is that we should encourage, not avoid, serious effort and thought in the finding of alternatives and the formulation of a thesis. Controversial topics 
make this task too easy. Pedagogically, it makes sense to begin with such live issues as abortion, where the theses are clear, and deeply felt opposing attitudes are on the surface. But we cannot end here. What characterizes intellectual inquiry is passionately argued alternatives about distant, narrow issues. Finally, controversial issues are detrimental from the point of view of furthering dialogue and inquiry in that they give too much attention to the difficulties of finding areas of mutual agreement.

Objection: Application of the reasonable alternative standard imposes evaluative criteria that go beyond the student's own goals or intentions; as a consequence they are likely to be unreliable.

Reply: This is really two related and important objections. In an article which summarizes "the new paradigm for teaching writing," one of the principal features listed is:

Instructors evaluate the written product by how well it fulfills the writer's intentions. . 10

Imposition of the reasonable alternative standard and related criteria does require evaluation, partially, on grounds external to the writer's intentions. It is one way of making more public and objective a teacher's grounds for evaluation. But it is not only in the formulation of a thesis that evaluation is external (or "extrinsic"). Good reasons are not simply statements that support a conclusion-they themselves require support. Whether a reason is a good one for a particular thesis depends upon the value of the alternative chosen, and how well the reason shows that thesis to advantage over this rival. These are largely external matters. So I am committed to rejecting this aspect of the 'new paradigm.'

Purely internal evaluation is especially dangerous as it encourages an indifference to the essay's substance, and downplays the value of writers challenging themselves. Suggesting that teachers suspend their own views, even if that were possible, amounts to endorsing refusal on the teacher's part to take the writer's ideas seriously. It is a refusal to engage in straight discussion and commentary. In a straight discussion the defense of an opposed thesis is not treated as merely a practical exercise. Suspension of belief raises teachers above exposing and testing their own biases, so that there is no real engagement with the student's ideas.

The second part of this objection might concede the desirability of external evaluation, in principle. ${ }^{11}$ But the objection is that in practice such evaluation is likely to be highly unreliable.

The reasonable alternative standard does offer some hope that we can mitigate this legitimate worry. First, the judgments called for are neither complete comparative judgments, which order all theses from best to worst, nor quantitative ones. They are judgments that the student has satisfied a certain minimal standard of acceptability. So they do not require exacting evaluations.

Second, identifying some reasonable alternatives to a given thesis usually comes with knowledge of the issues that the thesis addresses. So we can presume that this knowledge is shared by different readers. My examples concerning the issues of apartheid and free speech illustrate this claim.

\section{Constraining and Stimulating: A Misleading Contrast}

The rationale behind the approach taken here is, broadly, to reconstruct and impose principles of good inquiry on students' essay. This approach tightens, rather than loosens, constraints on students. Consequently, it is at odds with some fundamental tenets of contemporary composition practice and a research programme that is consonant with it. I shall confront the research programme after clarifying a potential misunderstanding. 
Nothing in what has been said implies that one cannot start writing until one has a good thesis. Ideally, the final thesis should be formulated well along in an exploration in which successive theses have been modified or abandoned by reference to objections and alternatives. In fact, the initial thesis does not matter much. One puts forward a thesis to get inquiry going, but it is often a mark of real intellectual struggle that the opening position shifts as work proceeds.

One can agree that a student forced at the beginning to worry about dotting his i's and crossing his t's may be hampered by too many demands. Certain aids, such as the outline, may become mechanical and burdensome crutches. But it is a far reaching error, which, lies behind this objection, to oppose constraints on, or standards for, the acceptability of a thesis with stimulants to the generation of ideas. Maintaining that only the latter is beneficial to the discovery stage compounds the error.

The error can be brought out by observing the crucial transformation that befell the concept of heuristics when it entered English Departments from Cognitive Science.

The key point about heuristics in psychology was that they were imperfect strategies for problem-solving. In psychology a standard example of such a heuristic is to work back from a solution to the prior steps that would have to hold to get to the next step. In composition texts and articles heuristics have been transformed, mainly into techniques, such as brainstorming or word associations or creating metaphors, to stimulate the generation of ideas. ${ }^{12}$

From the point of view of inquiry, there is a striking difference between heuristic strategies in Cognitive Science and those in composition texts. Only the former can actually be offered as a justification or reason for a proposed solution. We can justify a step in the solution of a problem, such as one that follows the above heuristic of "working backwards," by showing that its assumption is required in order to get to the next step (the "sub-goal"). But techniques for generation can only serve as stimulants to discovery; they provide no justification of their outcomes. One doesn't support a thesis by citing the way it originated (e.g. by brainstorming).

Since it must remain relevant to the evaluation or justification of a thesis, the reasonable alternative standard helps the student to generate pertinent ideas. The standard provides direction to students in testing their theses by highlighting the central vulnerabilities of that thesis. As with the heuristic to "work backwards," our strategy serves a dual role-generative and selective. It is able to do this, unlike heuristics as they are now invoked in composition teaching, because the ideas encouraged must remain relevant to the main goal of solving the problem or defending (or articulating) the thesis. The context of discovery is subordinated to the context of justification.

\section{Conclusion}

We began by offering the concept of alternatives as one that illuminates a (compromising) path between parochialism and superficiality. Some transferability is willingly sacrificed for greater depth. Clearly, not all writing is argumentative, nor do all theses have serious competitors. We still have, though, a great deal of transferability because of the centrality of the argumentative essay, the large range of issues that are rightly conceived in terms of contrasting theses, and a shared interest in promoting "cultural literacy."13 The greater depth gained arises from both the emphasis on the quality of the content studied, as well as the educational richness of inquiry as a subject to be taught and modeled.

One way to now understand my criticism of approaches in composition that are limited mainly to heuristics, style, grammar, or the "writing process" 
itself is that they succumb to the 'scope' horn of the above dilemma. Any admixture of content is mistakenly thought to artificially limit the learning dimension, and encroach on the domain of subjectmatter teaching.

Nevertheless, nothing said here is intended to deny the value of each of these approaches within their proper domain. Rather, the insistence is that these domains are quite narrow. Since a bias toward the 'scope' horn of the dilemma, leaves one with little else to teach but form or process, the contributions each of these approaches can make is automatically blown out of proportion. Once we take seriously the notion that it is the quality of thoughts or arguments that are primary, much of the standard advice offered seems empty (e.g. give reasons) or arbitrary (e.g. give two reasons). Helpful heuristics (e.g. brainstorming, creating metaphors) and stimulants to discovery (e.g. freewriting), unconstrained by the requirements for a good argument become ends in themselves with results that are wasteful and intellectually barren. Style books that prescribe proper writing-such as the famous "Use definite, specific, concrete language" - suffer the danger of promoting an implicit ideology without offering resources for challenging that ideology. ${ }^{14}$

Further, recommending, say, extensive revision or consideration of other points of view are self-defeating by their very failure to offer a basis for differential application of these recommendations. Criteria are needed as to when revision is sufficient or when a thesis has been well supported or when an alternative is credible enough to warrant criticism. However, the "when" question, especially, the question of when inquiry should cease, is itself central to an inquiry into inquiry. Exploring inquiry renders the guides and values promoted in teaching writing themselves subjects for critical discussion. So, valuing honesty, community, and commitment can be defended within the same framework which recognizes truth as the main aim of inquiry. Trading-off scope for content opens up, then, the possibility of offering substantial, intellectually stimulating, guidance to students.

Now it might seem, and this is where the dilemma of transferability is strongly felt, that any such specific guidance can only be content-relative: it depends upon the issues under study. No doubt to a large extent this is true, but skeptical conclusions do not follow. For, first, the conditions for ceasing inquiry, such as to accept a hypothesis when it has been shown preferable to all current competitors, apply across a large number of inquiries. Second, the logic or principles of inquiry should be applicable to a given subject ahead of detailed research in that subject. If a student knows to look for the real alternatives to her thesis, she is then directed toward the kind of reasons ("discriminatory") that must be sought.

Dependence on content in the use of strategies of inquiry does not then imply content-relativity in how they are taught or defended; nor does it imply serious content limitations in their range of potential applications. ${ }^{15}$

\section{Notes}

*I want to thank for helpful comments: Eugene Garver, Matthew Lipman, Beth Robertson, Marsha Silver, Carol Stanger, and especially Catherine Elgin.

For a presentation of this opposition in the context of critical thinking see John McPeck Critical Thinking and Education. St. Martin's Press. 1981. McPeck continually inflates his valuable critical points, through reliance on this false dilemma between maximally transferrable, but thereby contentless and empty advice; and substantive advice, that remains parochial to the subject-matter in which it is conveyed. 
See, for example, the early essays in Karl Popper Conjectures and Refutations. Basic Books, 1962.

Important philosophical work on the notion of alternatives, particularly as it bears on pragmatics, explanation, and inference is to be found in a number of authors. For one example see Bas Van Frassen The Scientific Image, Oxford University Press, 1980. This research is unappreciated in the informal logic community. The only text I know that gives the notion anything like its appropriate role in inference and argument is Larry Wright's Better Reasoning, Holt, Rinehart, and Winston, 1981.

4 For distantly related arguments, see Donald Davidson Inquiries into Truth and Interpretation, Oxford University Press, 1984. Especially, the sections "Radical Interpretation" and "Language and Reality."

For a persuasive example illustrating how agreement can be squeezed out of initially starkly opposed viewpoints see Samuel Gorovitz, Doctors' Dilemmas: Moral Conflict and Medical Care. Oxford University Press, 1982. Part two sections 7 and 8 . Gorovitz shows how this enlarged, even if limited, agreement can serve as a basis for moving dialogue ahead, increasing mutual understanding, and blunting stark oppositions.

Susan Horton's discussion of formulating a thesis (Thinking Through Writing, The John's Hopkins University Press, 1982. Ch.14, Stage 7) iflustrates the problem that I want to address. She gives almost all her attention to giving students ideas for generating a thesis, but largely ignores providing standards for a good thesis or for systematically relating the strength of the thesis to other aspects of inquiry.

6 We can think of how worthwhile a thesis is in terms of how well it optimizes informativeness and truth- fulness. As a thesis is less certain, it increases in 'surprise value' or informativeness. But if its truth is too surprising, it is no longer credible.

7 See W.V. Quine and J.S. Ullian, The Web of Belief. Random House, 1978. Ch.VI.

8 Actually, sometimes an interesting, but less obvious, alternative hypothesis does exist in these cases: "The evidence is insufficient to determine what caused the destruction of the dinosaurs."

9 Wayne C. Booth, "Boring from Within: The Art of the Freshman Essay," in The Norton Reader. Third Edition. Aruthur M. Eastman, et.al., eds. W.W. Norton \& Co. Inc. New York, 1973. 202-213.

10 Hairston, Maxine. "The Winds of Change: Thomas Kuhn and the Revolution in the Teaching of Writing." College Composition and Communication 33, 1982: 76-88. Quote on pg. 86.

11 E.D. Hirsch, Jr., who offers the best defense of purely intrinsic evaluation, forcefully raises the problem of reliability. Also, he clearly admits, with characteristically blunt honesty, some real shortcomings in restriction to mainly intrinsic evaluation. See his, The Philosophy of Composition, The University of Chicago Press, 1977. 182-185.

12 In Maimon, E.P., Belcher, G.L., Hearn, G.W., Nodine, B.F., and O'Connor, F.W. Writing in the Arts and Sciences. (Winthrop Publishers, Inc. Cambridge, Mass., 1981) the following definition of heuristics is offered:

Strategies to help you discover ideas and to learn more about a topic; opposed to rules in that heuristics can lead in many directions and do not guarantee a single right answer.

The most well-known attempt to apply the notion of heuristics from cognitive science to the teaching of writing is in the work of Flower and 
Hayes see, for example, Flower, L., and Hayes, J.R. "Problem-Solving Strategies and the Writing Process." College English 39 (1977): 449-461.

13 E.D. Hirsch, Jr.'s recent switch to an emphasis on content and a rejection of "educational formalism" supports this particular point. See his Cultural Literacy: What Every American Needs to Know, Houghton Mifflin Co., Boston 1987.

14 See Richard Ohmann, "Use Definite, Specific, Concrete Language." College English 41, 1979: 390-397. (The rule comes originally from the famed handbook of Strunk and White. MacMillan, 1979.)

15 The empirical issues, particularly regarding transferability, are complex and controversial. For a judicious recent review see Deanna Kuhn, "Education for Thinking" Teachers College Record Vol.87 1986. 495-511.

Dr. Jonathan Adler, Department of Philosophy, Brooklyn College, CUNY, Brooklyn, NY 11210 